\title{
Developmental risks and psychosocial adjustment among low-income Brazilian youth
}

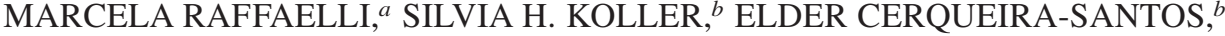 \\ AND NORMANDA ARAÚJO DE MORAIS ${ }^{b}$ \\ ${ }^{a}$ University of Nebraska-Lincoln; and ${ }^{b}$ Universidade Federal do Rio Grande do Sul, \\ Porto Alegre, Brasil
}

\begin{abstract}
Exposure to developmental risks in three domains (community, economic, and family), and relations between risks and psychosocial well-being, were examined among 918 impoverished Brazilian youth aged 14-19 ( $M=15.8$ years, $51.9 \%$ female) recruited in low-income neighborhoods in one city in Southern Brazil. High levels of developmental risks were reported, with levels and types of risks varying by gender, age, and (to a lesser extent) race. Associations between levels of risks in the various domains and indicators of psychological (e.g., self-esteem, negative emotionality) and behavioral (e.g., substance use) adjustment differed for male and female respondents. Findings build on prior research investigating the development of young people in conditions of pervasive urban poverty and reinforce the value of international research in this endeavor.
\end{abstract}

In recent decades, scholars have devoted considerable effort to understanding factors that promote or hinder the healthy development of children and adolescents. This research has allowed the identification of individual, familial, and community factors associated with psychosocial outcomes among young people (e.g., Luthar, 1991; Masten \& Garmezy, 1985; Masten, Miliotis, Graham-Bermann, Ramirez, \& Neeman, 1993; Sameroff, Gutman, \& Peck, 2003) and generated considerable evidence that

This study was funded by grants from the World Bank and $\mathrm{CNPq}$ to Silvia H. Koller. Manuscript preparation was partially supported by a Faculty Development Fellowship to Marcela Raffaelli from the College of Arts and Sciences, University of Nebraska-Lincoln, and by a Visiting Fellowship at the Key Centre for Women's Health in Society, School of Population Health at the University of Melbourne. The authors acknowledge the assistance of J'aims Ribeiro in developing the questionnaire.

Address correspondence and reprint requests to: Marcela Raffaelli, Department of Psychology and Institute for Ethnic Studies, University of Nebraska-Lincoln, Lincoln, NE 68588-0308; E-mail: mraffaelli1@unl.edu. exposure to risk factors is linked to decrements in psychological, behavioral, and social adjustment (e.g., Compas, Howell, Phares, Williams, \& Giunta, 1989; Cowan, Cowan, \& Schulz, 1996; DuBois, Felner, Brand, Adan, \& Evans, 1992; Gutman, Sameroff, \& Cole, 2003). For example, exposure to stressful life events has been linked to psychological distress, psychopathology, and substance abuse (see Clark \& Miller, 1998, for review). The extent to which these findings are generalizable to all populations of young people is unclear, however, and work on developmental psychopathology has been critiqued for lacking an international perspective (e.g., Luthar \& Zelazo, 2003; Wyman, 2003). In the current paper, we examined exposure to different developmental risks, and relations between risk factors and psychosocial well-being, in a sample of Brazilian young people.

Much of the prior work on developmental risk and resilience has been guided by an ecological perspective (e.g., Brooks-Gunn, 1995; Engle, Castle, \& Menon, 1996; Garbarino, 
2001; Luthar, Cicchetti, \& Becker, 2000). Similarly, our work draws on Bronfenbrenner's bioecological or ecological framework (e.g., Bronfenbrenner, 1979, 2004; Bronfenbrenner \& Morris, 1998), which offers a useful lens for studying development because it demands that attention be paid to multiple levels of influence and to factors both within and outside the individual, including the larger context. Latin American countries represent developmental contexts that differ dramatically from those found in North America and Europe. In most Latin American countries, the population is disproportionately likely to be young, which imposes a tremendous burden on already inadequate social institutions (e.g., schools, apprenticeship programs, health services; Welti, 2002). Moreover, over one-third (36\%) of the population in Latin America and the Caribbean lives below the poverty line (World Bank, 2003). Violence is also pervasive in Latin America (Concha-Eastman, 2002); of the 10 countries with the highest murder rates in the world, 7 are in Latin America, with young men being particularly affected. This context provides unique opportunities for examining development under conditions of adversity, and broadening understanding of child development and psychopathology.

\section{The Brazilian Context}

Brazil, where our study was conducted, has the world's fifth largest population and eighth largest economy (in terms of the gross national product). Its major cities possess modern infrastructures (e.g., international airports, state of the art transportation systems) and advanced medical and educational systems. Despite living in a wealthy and industrialized nation, however, many Brazilian children and adolescents experience pervasive poverty, with over one-third of families with children aged 14 or under subsisting on half of the minimum wage ${ }^{1}$ per capita or less (Instituto Brasileiro de Geografia e Estatística, 2004). According to the World Bank (2003), Brazil's high levels

1. The monthly minimum wage was approximately US $\$ 80$ in 2003 (BBC News, 2004). of poverty stem in large part from extreme income inequality (the poorest $20 \%$ of the Brazilian population receives just $2.6 \%$ of the nation's total income) and limited access to higher education (in 1999, just $35 \%$ of the working age population had graduated from secondary school). The current situation of Brazilian youth is also characterized by high levels of violence. A recent analysis of 67 countries revealed that Brazil had the fourth highest homicide rate in the world and was fifth in youth homicides (Waiselfisz, 2004; see also Concha-Eastman, 2002). Many young people are affected by pervasive violence in their communities, much of it linked to the drug trade. In addition, youngsters growing up in poverty may be targets of official violence that represents a legacy of Brazil's recent history of military rule (Diversi, Moraes, \& Morelli, 1999). Despite changes instituted after the restoration of civilian rule in 1985, official violence toward impoverished youth continues (Krug, Dahlberg, Mercy, Zwi, \& Lozano, 2002).

The impact of family stress, economic deprivation, and violence on young people in Brazil (and other Latin American countries) is largely unknown. Considerable research has been conducted with children and adolescents found in street settings (i.e., "street youth"; see Raffaelli, 1999; Raffaelli \& Larson, 1999; Rizzini, 1996), but less attention has been paid to the far larger population of impoverished youth (Rizzini, Barker, \& Cassaniga, 2002). Recently, Verner and Alda (2004) described findings from a large-scale study of 10- to 24-year-olds from low-income urban neighborhoods in the northeastern Brazilian city of Fortaleza. Respondents were at considerable risk for father absence $(93 \%)$ and low parental education (e.g., $76 \%$ of mothers had not completed primary school); respondents also reported high rates of early parenthood $(31 \%$ became parents by age 16), familial sexual or physical abuse $(6 \%$ had their first sexual relationship with a family member, and $13 \%$ reported violence in their home), and neighborhood violence (85\% of youth felt unsafe in their neighborhood). However, this study did not report outcomes associated with these risk factors, which have been linked to negative 
developmental outcomes in studies conducted in the United States and Europe.

\section{Overview of the Current Paper}

We drew on existing data from a large-scale study of impoverished youth conducted in southern Brazil (Koller, Ribeiro, CerqueiraSantos, Morais, \& Teodoro, 2005). The original study was financed by the World Bank and was designed to examine the life circumstances of impoverished young people in southern Brazil, and generate data that could be compared to prior studies of impoverished young people in other parts of Brazil and Latin America. Questions on psychological and behavioral adjustment were added by the local investigators. Drawing on this unique data set, three research questions were addressed.

What types of threats to development do impoverished Brazilian youth experience? Because of the lack of basic information on this population, we felt it was important to describe the extent to which youth experience specific developmental risks. Prior studies have considered anywhere from 5 to over 100 possible risk factors and vary widely in what variables are included (e.g., Forehand, Biggar, \& Kotchick, 1998; Garmezy \& Tellegen, 1984; Gest, Reed, \& Masten, 1999; Gutman et al., 2003; Turner \& Lloyd, 2003). The present study included measures of family, economic, and community risk factors comparable to those examined in prior research. Family risk factors identified in prior research include parental divorce and conflict (Forehand et al., 1998), education level (DeGoede, Sprujit, \& Maas, 1999), and physical and sexual abuse (Margolin \& Gordis, 2000). Economic risk factors include parental unemployment (DeGoede et al., 1999). The most studied community risk is violence, which has been linked to psychological and behavioral outcomes among young people in the United States (GorhamSmith \& Tolan, 1998; Schwab-Stone et al., 1995). In the first set of analyses, we examined the extent to which impoverished Brazilian young people are exposed to different developmental risks in the family, economic, and community domains.
To what extent are different types of risks linked to psychological and behavioral adjustment? US-based research indicates that higher levels of risk exposure are linked to decrements in psychological and behavioral adjustment (e.g., Clark \& Miller, 1998; Compas et al., 1989; DuBois et al., 1992). For example, exposure to violence in the family and in the community is associated with externalizing and internalizing problems (see Margolin \& Gordis, 2000, for review). Similarly, we expected that risk levels and adjustment would be associated; however, given the unique population and setting, we did not know whether specific types of risks would be associated with different aspects of adjustment. In the second set of analyses, we examined associations between each type of risk (family, economic, and community) and psychological and behavioral adjustment.

To what extent do risk exposure, and relations between risk and developmental outcomes, vary by gender, age, and race? On the basis of prior research conducted in the United States, we expected to find gender differences in risk exposure and in associations between risks and outcomes. For example, girls and boys report different levels of exposure to violence (Farrell \& Bruce, 1997) and differ in reactions to adverse events, with girls exhibiting psychological distress and boys exhibiting externalizing outcomes (Fergusson \& Horwood, 2003; Jenkins \& Bell, 1994). Other work has shown that youngsters of different ages may react differently to the same types of risks (Margolin \& Gordis, 2000). Thus, we examined gender and age differences in all analyses. Moreover, because recent work in Brazil indicates that race/ ethnicity is associated with developmentally relevant experiences (e.g., prenatal care and childhood nutritional status; Burgard, 2002, 2004), and may thus serve as a marker of additional risk, we also explored racial differences in the analyses.

\section{Method}

\section{Participants}

The original study targeted low-income adolescents and young adults in the city of Porto 
Alegre, Brazil, and was conducted in schools in impoverished neighborhoods and in institutions serving out-of-school youth (e.g., nongovernmental organizations, community centers). The original sample consisted of 1,024 adolescents and young adults; for the current analysis, we focused on the 918 respondents aged $14-19$ (89.6\% of the original respondents). The analytic sample consisted of 476 young women (51.9\%) and 442 young men (48.1\%) with an average age of 15.79 years $(S D=1.37)$. Most respondents were unmarried $(92.7 \% ; 2.4 \%$ were married, $0.4 \%$ separated or widowed, and $4.5 \%$ indicated "other" as their marital status).

\section{Procedures}

Consistent with the goals of the funding agency, the sampling strategy was aimed at identifying low-income youth. Using data from the 2000 Brazilian census (Instituto Brasileiro de Geografia e Estatística, 2003), each of the city's neighborhoods was characterized on five indicators: (a) salary of head of household, (b) educational level of head of household, (c) construction material of family home, (d) whether the house has running water, and (e) whether the house has indoor plumbing. Neighborhoods in the bottom $10 \%$ on two or more indicators were identified. The resulting 27 neighborhoods represented three major sections of the city; 10 neighborhoods were randomly selected to maintain the same proportional representation. Lists of municipal and state public schools were obtained from the state and city Departments of Education and one school from each neighborhood was randomly selected for recruitment. Each of the 10 schools was visited by study personnel who described the research goals and discussed data collection procedures. Brazilian public schools offer three sessions (morning, afternoon, evening) that are attended by different groups of students, and data collection activities were distributed across the various sessions. The out-of-school sample was recruited through institutions identified by school personnel within the selected neighborhoods, and through contacts established during the research team's prior work with homeless youth.

Youth completed the questionnaire in groups during 2-hr sessions supervised by trained graduate and undergraduate research assistants. The consent form was read aloud to inform youth about the purpose of the study, confidentiality procedures, and the availability of psychological services. The researchers then provided instructions on completing the questionnaire. Youth filled out the questionnaire individually; research assistants helped youth with physical disabilities or reading difficulties complete the measures.

\section{Measures}

The current study focuses on a subset of the measures assessed in the questionnaire. Descriptive statistics are shown in Table 1 (risk variables) and Table 2 (outcome variables).

Demographic variables. Respondents indicated their gender, coded as $1=$ male $(48.1 \%)$ and $2=$ female $(51.9 \%)$. Age was measured in years, recoded into a three-level variable for descriptive analyses: $1=14$ - to 15-year-olds (45.9\%), $2=16$ - to 17-year-olds $(41.8 \%)$, $3=18$ - to 19-year-olds $(12.3 \%)$. Youth selfidentified as White $(60.8 \%)$, Black $(20.5 \%)$, mixed race $(13.2 \%)$, indigenous $(4.0 \%)$, or Asian (1.5\%). A dichotomous variable was created for use in descriptive analyses, $1=$ White $(60.8 \%), 2$ = non-White $(39.2 \%)$.

Community risk factors. Youth completed four yes/no items asking if their neighborhoods had drug trafficking, police raids, assaults/ robberies, and shootouts. An overall index was created by counting the "yes" responses.

Economic risk factors. Three yes/no questions assessed economic risk: "The economic level of my family decreased suddenly," "Someone in my house is unemployed," and "I have gone hungry." An overall index was created by counting the number of "yes" responses.

Family risk factors. Five aspects of respondents' family situation were considered. Re- 
Table 1. Descriptive statistics for individual risk factors and summary indexes (overall and by gender)

\begin{tabular}{|c|c|c|c|c|c|c|}
\hline \multirow[b]{2}{*}{ Variable (Actual Range) } & \multicolumn{3}{|c|}{ Mean $(S D)$ on Risk Index } & \multicolumn{3}{|c|}{$\begin{array}{l}\text { Percentage Reporting } \\
\text { Each Risk Factor }\end{array}$} \\
\hline & Males & Females & All & Males & Females & All \\
\hline Community risk index $(0-3)$ & $1.06(0.66)$ & $0.93(0.57) * *$ & $0.99(0.62)$ & & & \\
\hline Drug trafficking & & & & 62.4 & 58.9 & 60.6 \\
\hline Police raids & & & & 48.4 & $41.7 \dagger$ & 44.9 \\
\hline Theft/assaults & & & & 48.4 & 48.0 & 48.2 \\
\hline Shootouts & & & & 56.0 & $50.2 \dagger$ & 53.0 \\
\hline Economic risk index $(0-3)$ & $0.78(0.79)$ & $0.90(0.85) \dagger$ & $0.84(0.82)$ & & & \\
\hline Economic level dropped & & & & 24.1 & $30.3^{*}$ & 27.4 \\
\hline Unemployed family member & & & & 49.2 & 51.2 & 50.2 \\
\hline Have gone hungry & & & & 7.0 & $10.9 \dagger$ & 9.1 \\
\hline Family risk index $(0-4)$ & $0.95(0.82)$ & $1.08(0.89) \dagger$ & $1.01(0.86)$ & & & \\
\hline Neither parent alive & & & & 1.6 & 2.1 & 1.9 \\
\hline Parents separated & & & & 35.4 & 36.6 & 36.0 \\
\hline Low parental education & & & & 38.5 & 41.2 & 39.9 \\
\hline Family member in prison & & & & 20.8 & 25.3 & 23.2 \\
\hline Physical or sexual abuse & & & & 1.6 & $4.6^{*}$ & 3.2 \\
\hline Composite risk index $(0-11)$ & $3.84(2.11)$ & $3.95(2.16)$ & $3.90(2.13)$ & & & \\
\hline
\end{tabular}

Note: $N=918$ (442 males, 476 females).

Significance of gender differences in risk indexes (univariate ANOVAs controlling for age and race) and likelihood of reporting each specific risk (one-way ANOVAs and chi-square tests with continuity correction): $\dagger p<.10$. ${ }^{*} p<.05$ $* * p<.01$.

Table 2. Descriptive statistics for psychological and behavioral adjustment indicators (overall and by gender)

\begin{tabular}{|c|c|c|c|c|c|c|}
\hline \multirow[b]{2}{*}{ Variables (Actual Range) } & \multicolumn{3}{|c|}{ Mean $(S D)$} & \multicolumn{3}{|c|}{ Percentage Yes } \\
\hline & Males & Females & All & Males & Females & All \\
\hline \multicolumn{7}{|l|}{ Psychological adjustment indicators } \\
\hline Self-esteem (1.4-3) & $2.45(0.36)$ & $2.47(0.37)$ & $2.46(0.36)$ & & & \\
\hline Positive emotionality (1-3) & $2.58(0.41)$ & $2.57(0.39)$ & $2.58(0.40)$ & & & \\
\hline Negative emotionality (1-3) & $1.71(0.44)$ & $1.77(0.45) \dagger$ & $1.74(0.45)$ & & & \\
\hline \multicolumn{7}{|l|}{ Behavioral adjustment indicators } \\
\hline Licit substance use $(0-3)$ & $1.44(1.03)$ & $1.65(1.05) * *$ & $1.55(1.04)$ & & & \\
\hline Illicit substance use (\% yes) & & & & 10.2 & 10.7 & 10.5 \\
\hline Alcohol use past month $(0-3)$ & $0.71(0.95)$ & $0.73(0.94)$ & $0.72(0.94)$ & & & \\
\hline Ever attempted suicide (\% yes) & & & & 4.4 & $14.3 * * *$ & 9.5 \\
\hline
\end{tabular}

Note: The total numbers $(N)$ vary from 853 to 918 because of missing data on specific variables; maximum $N=442$ males and 476 females.

Significance of gender differences (one-way ANOVAs for continuous variables and chi-square tests with continuity correction for categorical variables): $\dagger p<.10$. $* * p<.01$. $* * * p<.001$.

spondents answered a set of yes/no questions indicating whether each of their parents was alive (recoded as $1=$ one or both alive, $2=$ neither alive), whether their parents were sep- arated $(1=n o, 2=y e s)$, and whether anyone in their family was in jail $(1=n o, 2=y e s)$. They also reported the highest grade each parent had completed (recoded as $1=$ one or both 
parents completed primary school, $2=$ neither parent completed primary school).

Respondents also completed a set of questions about experiences of physical (e.g., yelling, threatening verbally or with weapons, hitting with fist or weapons) and sexual abuse while living at home, using a 5-point scale to indicate the frequency of each type of abuse $(1=$ never, 3 = rarely, $5=$ very frequent $)$. Two abuse composites were created by averaging; because 110 of the respondents had skipped at least one of the abuse items, scale scores were computed for respondents who had answered six of the nine physical abuse items, and two of the three sexual abuse items. Preliminary analyses revealed that $2.6 \%$ of respondents reported any physical abuse $(1.4 \%$ of males, $3.6 \%$ of females), and $0.8 \%$ reported any sexual abuse $(0.2 \%$ of males, $1.3 \%$ of females). Because of the relatively low incidence of abuse, and the fact that more young women than men reported both types of abuse, the two items were combined to form one dichotomous item indicating the presence or absence of any abuse.

A composite family risk index was then created by counting which of the five family risks were present (neither parent alive, parents separated, family member imprisoned, neither parent completed primary school, and presence of abuse).

Composite risk index. An overall risk index was created by counting the total number of family, economic, and community risk factors. The resulting variable could range from 0 to 12 .

Psychological adjustment. The questionnaire assessed different aspects of psychological adjustment using items taken from existing measures and items created for the study. All items were rated on a 3 -point scale $(1=$ disagree, $2=$ neither agree nor disagree, $3=$ agree $)$. Before creating scales, principal components factor analyses and reliability analyses were conducted on sets of items intended to assess specific aspects of adjustment. After the final set of items was selected for inclusion in each scale, scores were computed by averaging. Respondents must have answered at least $66 \%$ of the items to receive a score on a particular scale.

Eleven items assessing self-esteem were included on the questionnaire. Ten were equivalent to those on the original Rosenberg SelfEsteem Scale (Rosenberg, 1979) but 1 item ("I wish I could have more respect for myself") had an unacceptably low item-total correlation (.17) and was dropped and replaced by another item ("I am ashamed of the way I am"). Principal components factor analysis yielded a two-factor solution, with the first factor (eigenvalue $=3.0,30.25 \%$ variance) consisting of positively worded items (e.g., "I feel that I have a number of good qualities"), and the second factor (eigenvalue $=1.58$, $15.79 \%$ variance) consisting of negatively worded items (e.g., "At times I feel I am no good at all"). Item-total correlations for the 10 items ranged from .22 to .51 ( 7 were over .35). To maintain consistency with the original scale, a single score was computed to reflect overall self-esteem (10-item $\alpha=.73$ ). US-based research conducted with adolescents from multiple ethnic groups has reported $\alpha=.79-.85$ for the original Rosenberg Self-Esteem Scale (Umaña-Taylor \& Fine, 2001).

Respondents indicated the extent to which they experienced positive and negative emotions and feelings. Many of these items were comparable to those on the Positive and Negative Affect Schedule for Children (PANAS-C; Laurent et al., 1999), which has been adapted for use in Brazil (Giacomoni, 2002). Of the six positive items administered in the questionnaire, five are on either the English or Portuguese version of the PANAS-C (i.e., happy, calm, cheerful, lively, satisfied) and one was added ("I enjoy life"). All six items had item-total correlations that exceeded .35 (range $=.37-.51)$. The factor analysis yielded a two-factor solution: the first factor had an eigenvalue of 2.46 (40.98\% variance), but the second had a lower eigenvalue $(1.08 ; 17.9 \%$ variance) and several items loaded on both factors. Thus, a single score was computed to reflect positive emotionality (six-item $\alpha=.71$ ). Four of the eight negative items are on the original or adapted PANAS (sad, depressed, irritated, gloomy) and four were added to tap 
into negative thoughts and feelings (need attention, like to fight, have negative memories of childhood, don't like to think about the past). All of the item-total correlations exceeded .30 (range $=.32-.57$ ), and a singlefactor solution emerged from the principal components factor analysis (eigenvalue $=2.9$, $36.25 \%$ variance). A single score was computed to reflect negative emotionality (eightitem $\alpha=.74)$. In the original PANAS-C validation studies (Laurent et al., 1999), positive affect yielded either two or three factors, but was found to be unidimensional in both studies ( $\alpha=.89-.90)$; negative affect yielded a one-factor solution $(\alpha=.92-.94)$.

Behavioral adjustment. Two areas of behavioral adjustment were examined: suicidality and substance use. Lifetime suicide attempts were assessed by asking whether the respondent had ever attempted suicide $(1=n o, 2=$ yes). Substance use was assessed with a set of items developed by the Brazilian Center for Information on Psychotropic Drugs at the University of São Paulo Medical School for use in national studies, including household surveys (Carlini, Galduróz, Noto, \& Nappo, 2002) and national surveys of secondary school students (Galduróz, Noto, \& Carlini, 1997). Youth indicated whether they had ever tried each of 10 licit (wine/beer, hard liquor, cigarettes) and illicit (marijuana, hashish, shoemaker's glue, loló [solvents such as ether, perfume, or paint thinner mixed with flowers and fruits], inhalants, cocaine, and crack) substances. A licit substance use index was created by counting the number of legal substances tried; this variable could range from 0 to 3. An illicit substance use index was created by counting the number of illegal substances used; the resulting variable could range from 0 to 7. A high proportion of the sample $(89.3 \%)$ did not report any illicit drug use; therefore, a dichotomous variable was created to reflect lifetime use of any illicit drugs $(1=n o, 2=y e s)$. In addition, one question assessed alcohol use in the past month, rated on a 4-point scale $(0=$ no use, $1=$ used on 1-3 days, 2 = used on 4-19 days, $3=$ used on 20 or more days).

\section{Plan of analysis}

Descriptive analyses of overall risk scores and individual variables used in the family, economic, and community risk indexes were conducted, and gender, age, and racial differences examined. Linkages between family, economic, and community risks, and psychological and behavioral adjustment, were explored by computing bivariate correlations and regressions (linear regressions for continuous outcome measures and logistic regressions for dichotomous outcomes). Individual characteristics (age, gender, race) were entered on the first step in each regression model, the three risk indexes were entered on the second step, and interaction terms for Gender $\times$ Risk Score and Age $\times$ Risk Score were entered on the third step (continuous variables were centered before interaction terms were computed). This initial set of analyses revealed a number of interactions between gender and risk scores; to facilitate interpretation of the interactions, the models were recomputed separately by gender.

\section{Results}

\section{Descriptive analyses of risks: Overall} patterns and differences because of age, gender, and race

The first set of analyses examined threats to development experienced by impoverished Brazilian youth and explored age, gender, and racial differences in risk scores. Mean scores on the risk indexes, and frequency of endorsement of each individual risk factor, are displayed in Table 1. Respondents reported an average of 3.9 risks (range $=0-11$ ); endorsement of individual risk items ranged from a low of $1.9 \%$ (neither parent alive) to a high of $60.6 \%$ (presence of drug trafficking in the community).

Four univariate analyses of variance (ANOVAs) were computed (one for each risk domain and the overall risk index) to examine differences in risk scores attributable to gender, age group, and race, as well as interactions between demographic characteristics. Significant effects emerged for the family risk 
Table 3. Mean (SD) age differences in risk levels by gender and overall

\begin{tabular}{lcccc}
\hline \hline & \multicolumn{3}{c}{ Age Group } & \\
\cline { 2 - 4 } & $14-15$ & $16-17$ & $18-19$ & ANOVA Results \\
\hline Community risks & & & & \\
$\quad$ Males & $0.98(0.66)$ & $1.10(0.66)$ & $1.17(0.66)$ & $F=2.71 \dagger ; \eta^{2}=.012$ \\
$\quad$ Females & $0.90(0.55)$ & $0.94(0.61)$ & $1.04(0.54)$ & $F=1.39 ; \eta^{2}=.006$ \\
$\quad$ All & $0.93(0.61)$ & $1.02(0.64)$ & $1.11(0.61)$ & $F=3.27^{*} ; \eta^{2}=.007$ \\
Economic risks & & & & \\
$\quad$ Males & $0.74(0.80)$ & $0.73(0.75)$ & $1.00(0.82)$ & $F=3.07^{*} ; \eta^{2}=.014$ \\
$\quad$ Females & $0.85(0.85)$ & $0.91(0.82)$ & $1.10(0.98)$ & $F=1.84 ; \eta^{2}=.009$ \\
$\quad$ All & $0.80(0.83)$ & $0.83(0.79)$ & $1.04(0.89)$ & $F=3.46^{*} ; \eta^{2}=.008$ \\
Family risks & & & & \\
$\quad$ Males & $0.90(0.83)$ & $0.93(0.81)$ & $1.19(0.83)$ & $F=3.04 * ; \eta^{2}=.014$ \\
$\quad$ Females & $1.00(0.87)$ & $1.12(0.83)$ & $1.24(1.11)$ & $F=1.92 ; \eta^{2}=.008$ \\
$\quad$ All & $0.96(0.85)$ & $1.03(0.82)$ & $1.21(0.96)$ & $F=4.18^{*} ; \eta^{2}=.009$ \\
$\quad$ Total risks & & & & \\
$\quad$ Males & $3.47(2.10)$ & $3.86(2.06)$ & $4.91(1.95)$ & $F=11.60^{* * *} ; \eta^{2}=.05$ \\
$\quad$ Females & $3.64(2.09)$ & $4.11(2.11)$ & $4.76(2.39)$ & $F=6.40^{* *} ; \eta^{2}=.026$ \\
$\quad$ All & $3.57(2.10)$ & $3.99(2.09)$ & $4.84(2.14)$ & $F=15.04^{* * *} ; \eta^{2}=.032$ \\
\hline
\end{tabular}

Note: $N=918$ (442 males, 476 females). Statistics for the overall sample are based on univariate ANOVAs controlling for gender and race.

Significant gender-specific results based on one-way ANOVAs conducted within gender: $\dagger p<.10$. $* p<.05 . * * p<.01 . * * * p<.001$.

index, $F(11,917)=2.61, p=.003$, partial $\eta^{2}=.031$; community risk index, $F(11,917)=2.62, p=.003$, partial $\eta^{2}=$ .031 ; and economic risk index, $F(11,917)=$ $2.24, p=.011$, partial $\eta^{2}=.026$. There were significant or trend-level main effects for age and gender on all three indexes, but only one race effect (family risk). No two-way or threeway interactions emerged. The ANOVA for the overall risk index was also significant, $F(11,917)=5.41, p=.000$, partial $\eta^{2}=$ .062 , with main effects for age and race (but not gender); again, none of the interactions were significant.

Mean scores on the risk indexes by gender are shown in Table 1. In analyses controlling for age and race, young men reported higher levels of community risk than young women, $F(1,917)=7.24, p=.007$, partial $\eta^{2}=.008$. Young women had marginally higher scores than young men: economic risk, $F(1,917)=$ $3.36, p=.067$, partial $\eta^{2}=.004$, and family risk, $F(1,917)=2.72, p=.099$, partial $\eta^{2}=$ .003 . No gender differences were found in overall risk scores.
Age-related patterns were examined within gender and overall (see Table 3 for means and ANOVA statistics). Age differences were seen in community risk scores (significant in the overall sample, and trend-level for males), economic risk scores (males and overall), family risk scores (males and overall), and total risk scores (males, female, and overall). In all cases, increasing age was associated with higher levels of risk.

Additional analyses (not shown) revealed that family risk levels were lower among White youth $(M=0.96, S D=0.84)$ than non-White youth $(M=1.11, S D=0.86), F(1,917)=$ 5.01, $p=.025$, partial $\eta^{2}=.005$; however, no race differences in levels of community and economic risk emerged. Scores on the overall risk index were lower among White $(M=$ $3.71, S D=2.06)$ than non-White youth $(M=$ $4.19, S D=2.22), F(1,917)=4.50, p=.034$, partial $\eta^{2}=.005$.

Taken as a whole, the first set of analyses indicated that levels and types of developmental risks experienced by impoverished Brazilian youth vary considerably by gender 
Table 4. Correlations between demographic variables and risk scores and indicators of adjustment

\begin{tabular}{|c|c|c|c|c|c|c|c|}
\hline & Age & Gender & Race & $\begin{array}{c}\text { Community } \\
\text { Risk }\end{array}$ & $\begin{array}{c}\text { Economic } \\
\text { Risk }\end{array}$ & $\begin{array}{l}\text { Family } \\
\text { Risk }\end{array}$ & $\begin{array}{l}\text { Total } \\
\text { Risk }\end{array}$ \\
\hline \multicolumn{8}{|l|}{ Psychological indicators } \\
\hline Self-esteem & .08 & .02 & -.03 & -.05 & $-.14 *$ & -.06 & $-.10 *$ \\
\hline Positive emotionality & .07 & -.01 & .02 & -.07 & $-.11 *$ & $-.10 *$ & $-.14 *$ \\
\hline Negative emotionality & -.01 & .06 & .015 & $.10 *$ & $.18^{*}$ & .08 & $.16 *$ \\
\hline \multicolumn{8}{|l|}{ Behavioral indicators } \\
\hline Licit substance index & $.11 *$ & $.10^{*}$ & -.04 & $.13^{*}$ & $.12 *$ & $.16^{*}$ & $.20 *$ \\
\hline Illicit substance & $.13 *$ & .01 & -.05 & $.16^{*}$ & $.10^{*}$ & .06 & $.16^{*}$ \\
\hline Alcohol last month & $.10^{*}$ & .01 & -.04 & $.14 *$ & .06 & $.09 *$ & $.17 *$ \\
\hline Suicide attempt & .01 & $.17 *$ & .045 & .05 & $.14^{*}$ & .06 & $.11 *$ \\
\hline
\end{tabular}

Note: The total numbers $(N)$ range from 853 to 918 . Categorical variable coding: gender $1=$ male, $2=$ female; race $1=$ White, 2 = non-White; illicit substance use and suicide attempt(s) $1=$ no, $2=$ yes.

${ }^{*} p<0.01$ level (two tailed), equivalent to an overall $p$ level of .05 (Bonferroni correction).

and age, with race playing a more limited role.

\section{Associations between risks and psychological and behavioral adjustment}

Before exploring associations between risks and adjustment, we examined intercorrelations among the risk scores, and among different indicators of adjustment. The majority of the correlations were in the small to moderate range: $r \mathrm{~s}=.10$ to .23 among the different domains of risk, -.29 to .55 among the psychological adjustment indicators, and .25 to .46 among the three drug use variables. None of the correlations between indicators representing different domains of adjustment (psychological vs. behavioral) exceeded .20. Therefore, no additional data reduction was conducted.

Bivariate correlations between adjustment indicators and demographic variables and the risk indexes are displayed in Table 4. Looking first at associations between demographics and adjustment indicators, no significant correlations emerged among age, gender, or race and the psychological indicators. Five of the 12 correlations between demographics and behavioral indicators were significant: age was positively associated with use of licit and illicit substances and frequency of alcohol use in the last month, and gender with licit substance use and past suicide attempts (young women were more likely than young men to report licit substance use and suicide attempts). None of the adjustment indicators were associated with race.

Turning next to correlations between risk indexes and adjustment indicators, increases in risk scores tended to be associated with decreased psychological functioning and increased behavior risks, but different indexes showed different patterns of association. Community risk was associated with negative emotionality and elevated substance use (all three indicators). Economic risk was significantly correlated with six of the psychological and behavioral indicators (increased poverty was associated with lower levels of self-esteem and positive emotionality, and with higher levels of negative emotionality, use of licit and illicit substances, and past suicide attempts). Respondents who reported higher levels of family risk reported lower levels of positive emotionality and more licit substance and recent alcohol use. The composite risk index showed significant associations with all of the psychological and behavioral indicators; in all cases, higher levels of risk were associated with lower levels of adjustment.

To examine whether risk scores contributed independently to psychological and behavioral adjustment, separate regression models were computed for male and female 
Table 5. Linear regressions predicting psychological adjustment from demographic variables and the three risk indexes for males

\begin{tabular}{|c|c|c|c|c|c|c|c|c|c|}
\hline & \multicolumn{3}{|c|}{ Self-Esteem } & \multicolumn{3}{|c|}{$\begin{array}{c}\text { Positive } \\
\text { Emotionality }\end{array}$} & \multicolumn{3}{|c|}{$\begin{array}{c}\text { Negative } \\
\text { Emotionality }\end{array}$} \\
\hline & $B$ & $S E B$ & $\beta$ & $B$ & $S E B$ & $\beta$ & $B$ & $S E B$ & $\beta$ \\
\hline \multicolumn{10}{|l|}{ Step 1} \\
\hline Age & 0.03 & 0.01 & $.11 *$ & 0.02 & 0.01 & $.08 \dagger$ & 0.01 & 0.02 & .02 \\
\hline Race & -0.02 & 0.04 & -.03 & 0.01 & 0.04 & .02 & -0.01 & 0.04 & -.02 \\
\hline \multicolumn{10}{|l|}{ Step 2} \\
\hline Age & 0.03 & 0.01 & $.13^{* *} *$ & 0.03 & 0.01 & $.10 \dagger$ & 0.00 & 0.02 & .00 \\
\hline Race & 0.00 & 0.04 & .00 & 0.02 & 0.04 & .03 & -0.03 & 0.04 & -.03 \\
\hline Community risk & -0.07 & 0.03 & $-.13^{* *}$ & -0.06 & 0.03 & $-.10 *$ & 0.09 & 0.03 & $.14 * *$ \\
\hline Economic risk & -0.05 & 0.02 & $-.10 \dagger$ & 0.00 & 0.03 & .00 & 0.04 & 0.03 & .07 \\
\hline Family risk & 0.00 & 0.02 & .00 & -0.01 & 0.03 & -.01 & -0.02 & 0.03 & -.03 \\
\hline \multicolumn{10}{|l|}{ Step 3} \\
\hline Age & 0.00 & 0.03 & -.01 & 0.00 & 0.03 & -.01 & 0.00 & 0.04 & .01 \\
\hline Race & 0.00 & 0.04 & .00 & 0.03 & 0.04 & .03 & -0.03 & 0.04 & -.03 \\
\hline Community risk & -0.07 & 0.03 & $-.13^{* *}$ & -0.06 & 0.03 & $-.10 *$ & 0.09 & 0.03 & $.14 * *$ \\
\hline Economic risk & -0.05 & 0.02 & $-.10^{*}$ & 0.00 & 0.03 & .00 & 0.04 & 0.03 & .07 \\
\hline Family risk & 0.00 & 0.02 & .00 & -0.01 & 0.03 & -.02 & -0.02 & 0.03 & -.03 \\
\hline Age $\times$ Community Risk & 0.03 & 0.02 & .14 & 0.02 & 0.02 & .07 & -0.01 & 0.02 & -.03 \\
\hline Age $\times$ Economic Risk & 0.02 & 0.02 & .07 & -0.01 & 0.02 & -.03 & 0.01 & 0.02 & .04 \\
\hline Age $\times$ Family Risk & -0.01 & 0.02 & -.03 & 0.02 & 0.02 & .09 & -0.01 & 0.02 & -.02 \\
\hline \multicolumn{10}{|l|}{ Step and model statistics } \\
\hline Step 1 & \multirow{4}{*}{\multicolumn{3}{|c|}{$\begin{array}{l}R^{2}=.012, F=2.51 \dagger \\
\Delta R^{2}=.028, \Delta F=4.06^{* *} \\
\Delta R^{2}=.008, \Delta F=1.10 \\
R^{2}=.048, F=2.58^{* *}\end{array}$}} & \multirow{4}{*}{\multicolumn{3}{|c|}{$\begin{array}{l}R^{2}=.007, F=1.53 \\
\Delta R^{2}=.01, \Delta F=1.39 \\
\Delta R^{2}=.005, \Delta F=0.69 \\
R^{2}=.022, F=1.16\end{array}$}} & \multirow{4}{*}{\multicolumn{3}{|c|}{$\begin{array}{l}R^{2}=.001, F=0.148 \\
\Delta R^{2}=.025, \Delta F=3.46^{*} \\
\Delta R^{2}=.001, \Delta F=0.16 \\
R^{2}=.027, F=1.39\end{array}$}} \\
\hline Step 2 & & & & & & & & & \\
\hline Step 3 & & & & & & & & & \\
\hline Model & & & & & & & & & \\
\hline
\end{tabular}

Note: Race coded $1=$ White, $2=$ non-White.

$\dagger p<.10 . * p<.05$. ** $p<.01$.

respondents (see Plan of Analysis). Individual characteristics (age, race) were entered on the first step, the three risk indexes (family, economic, community) on the second step, and interaction terms of Age $\times$ Risk Index were entered on the third step. Results are displayed in Tables 5-8; for ease of presentation, all step and model statistics are also presented in the tables.

Starting with psychological adjustment of male respondents (Table 5), none of the three models were significant at the first step, when age and race were entered. At the second step, two of the three models were significant, with specific risk indexes contributing to each model. Community and economic risk scores were associated with self-esteem (lower levels of each risk were associated with higher levels of self-esteem), and community risk scores were (positively) associated with negative emotionality. Only the model for selfesteem remained significant at the final step, when interaction terms were entered. Age was significantly (positively) associated with selfesteem on initial entry, but neither age nor race were significant in any of the models at the final step, and the interactions of Age $\times$ Risk did not contribute to the models.

In the four models for behavioral outcomes (Table 6), risk indexes were significant predictors of young men's adjustment on initial entry (Step 2 of each model) and in the final models, all of which were significant. Two of the three risk indexes were associated with licit drug use (community and family risks), and an interaction between age and economic risk also emerged. To interpret the significant interaction, we graphed licit substance use as a function of age group (14-15, 16-17, 1819) among young men who reported levels of economic risk at or below the median value (i.e., 0 or 1 risk factors; $80.5 \%$ of respondents) compared to those who reported two or three economic risk factors (19.5\%). As shown 
Table 6. Linear and logistic regressions predicting behavioral adjustment from demographic variables and the four risk indexes for males

\begin{tabular}{|c|c|c|c|c|c|c|c|c|c|c|c|c|}
\hline & \multicolumn{3}{|c|}{$\begin{array}{c}\text { Licit } \\
\text { Substance Use }{ }^{a}\end{array}$} & \multicolumn{3}{|c|}{$\begin{array}{l}\text { Alcohol Use } \\
\text { Last Month }^{a}\end{array}$} & \multicolumn{3}{|c|}{$\begin{array}{c}\text { Illicit } \\
\text { Substance Use }{ }^{b}\end{array}$} & \multicolumn{3}{|c|}{ Suicide Attempts ${ }^{b}$} \\
\hline & $B$ & $S E B$ & $\beta$ & $B$ & $S E B$ & $\beta$ & $B$ & $S E$ & $\exp (B)$ & $B$ & $S E$ & $\exp (B)$ \\
\hline \multicolumn{13}{|l|}{ Step 1} \\
\hline Age & 0.09 & 0.035 & $.12 *$ & 0.08 & 0.03 & $.13 *$ & $0.27 *$ & 0.11 & 1.31 & -0.14 & 0.18 & 0.87 \\
\hline Race & 0.04 & 0.10 & .02 & 0.06 & 0.09 & .03 & -0.21 & 0.33 & 0.81 & 0.55 & 0.49 & 1.70 \\
\hline \multicolumn{13}{|l|}{ Step 2} \\
\hline Age & 0.06 & 0.03 & $.08 \dagger$ & 0.07 & 0.03 & $.10 *$ & $0.21 \dagger$ & 0.12 & 1.23 & -0.21 & 0.19 & 0.81 \\
\hline Race & -0.05 & 0.10 & -.02 & 0.01 & 0.09 & .01 & -0.47 & 0.35 & 0.63 & 0.23 & 0.51 & 1.25 \\
\hline Community risk & 0.29 & 0.07 & $.19 * * *$ & 0.23 & 0.07 & $.16^{* *}$ & $1.21 * * *$ & 0.25 & 3.37 & $0.63 \dagger$ & 0.36 & 1.87 \\
\hline Economic risk & 0.02 & 0.06 & .01 & -0.05 & 0.06 & -.04 & 0.01 & 0.22 & 1.01 & $0.80 * *$ & 0.31 & 2.23 \\
\hline Family risk & 0.16 & 0.06 & $.13 * *$ & 0.09 & 0.06 & .08 & 0.25 & 0.20 & 1.30 & 0.08 & 0.31 & 1.08 \\
\hline \multicolumn{13}{|l|}{ Step 3} \\
\hline Age & 0.07 & 0.08 & .10 & 0.07 & 0.07 & .11 & 0.15 & 0.33 & 1.16 & 0.34 & 0.55 & 1.41 \\
\hline Race & -0.05 & 0.10 & -.02 & 0.01 & 0.09 & .01 & -0.48 & 0.35 & 0.62 & 0.18 & 0.52 & 1.20 \\
\hline Community risk & 0.28 & 0.07 & $.18 * * *$ & 0.21 & 0.07 & $.15 * *$ & $1.17 * * *$ & 0.26 & 3.21 & 0.58 & 0.37 & 1.78 \\
\hline Economic risk & 0.03 & 0.06 & .02 & -0.04 & 0.06 & -.03 & -0.02 & 0.23 & 0.98 & $0.86 * *$ & 0.32 & 2.36 \\
\hline Family risk & 0.16 & 0.06 & $.13^{*}$ & 0.09 & 0.06 & .08 & 0.33 & 0.20 & 1.39 & 0.02 & 0.31 & 1.00 \\
\hline Age $\times$ Community Risk & 0.03 & 0.05 & .06 & 0.03 & 0.05 & .05 & 0.12 & 0.17 & 1.13 & -0.27 & 0.31 & 0.77 \\
\hline Age $\times$ Economic Risk & -0.09 & 0.04 & $-.14 *$ & -0.07 & 0.04 & -.11 & 0.10 & 0.15 & 1.11 & 0.10 & 0.23 & 1.0 \\
\hline Age $\times$ Family Risk & 0.02 & 0.04 & .05 & 0.02 & 0.04 & .04 & -0.18 & 0.13 & 0.84 & -0.31 & 0.23 & 0.73 \\
\hline \multicolumn{13}{|l|}{ Step and model statistics } \\
\hline Step 1 & \multicolumn{3}{|c|}{$R^{2}=.014, F=3.22 *$} & \multicolumn{3}{|c|}{$R^{2}=.017, F=3.62 *$} & \multicolumn{3}{|c|}{$\chi^{2}=6.28 *$} & \multicolumn{3}{|c|}{$\chi=1.82$} \\
\hline Step 2 & \multirow{3}{*}{\multicolumn{3}{|c|}{$\begin{array}{l}\Delta R^{2}=.056, \Delta F=8.67 * * * \\
\Delta R^{2}=.010, \Delta F=1.50 \\
R^{2}=.080, F=4.68 * * *\end{array}$}} & \multirow{3}{*}{\multicolumn{3}{|c|}{$\begin{array}{l}\Delta R=.032, \Delta F=4.66 * * \\
\Delta R=.007, \Delta F=0.99 \\
R^{2}=.055, F=3.05 * *\end{array}$}} & \multicolumn{3}{|c|}{$\chi^{2}=27.69 * * *$} & \multicolumn{3}{|c|}{$\chi^{2}=11.73 * *$} \\
\hline Step 3 & & & & & & & $x^{2}=2.30$ & & & $x^{2}=2.92$ & & \\
\hline Model & & & & & & & \multicolumn{3}{|c|}{$\begin{array}{l}\chi^{2}=36.26 * * * \\
\text { Nagelkerke } R^{2}=.163\end{array}$} & \multicolumn{3}{|c|}{$\begin{array}{l}\chi^{2}=16.47 * \\
\text { Nagelkerke } R^{2}=.130\end{array}$} \\
\hline
\end{tabular}

Note: Race coded $1=$ White, 2 = non-White.

${ }^{a}$ Continuous outcome variable.

${ }^{b}$ Dichotomous outcome variable.

$\dagger p<.10 . * p<.05 . * * p<.01 . * * * p<.001$. 
Table 7. Linear regressions predicting psychological adjustment from demographic variables and the three risk indexes for females

\begin{tabular}{|c|c|c|c|c|c|c|c|c|c|}
\hline & \multicolumn{3}{|c|}{ Self-Esteem } & \multicolumn{3}{|c|}{$\begin{array}{c}\text { Positive } \\
\text { Emotionality }\end{array}$} & \multicolumn{3}{|c|}{$\begin{array}{c}\text { Negative } \\
\text { Emotionality }\end{array}$} \\
\hline & $B$ & $S E B$ & $\beta$ & $B$ & $S E B$ & $\beta$ & $B$ & $S E B$ & $\beta$ \\
\hline \multicolumn{10}{|l|}{ Step 1} \\
\hline Age & 0.02 & 0.01 & .06 & 0.01 & 0.01 & .05 & -0.01 & 0.02 & -.035 \\
\hline Race & -0.03 & 0.04 & -.04 & 0.02 & 0.04 & .03 & 0.05 & 0.04 & .05 \\
\hline \multicolumn{10}{|l|}{ Step 2} \\
\hline Age & 0.02 & 0.01 & $.09 \dagger$ & 0.03 & 0.01 & $.09 \dagger$ & -0.03 & 0.02 & $-.08 \dagger$ \\
\hline Race & -0.03 & 0.04 & -.03 & 0.03 & 0.04 & .04 & 0.04 & 0.04 & .04 \\
\hline Community risk & 0.04 & 0.03 & .06 & -0.01 & 0.03 & -.02 & 0.03 & 0.04 & .03 \\
\hline Economic risk & -0.08 & 0.02 & $-.19 * * *$ & -0.08 & 0.02 & $-.17 * * *$ & 0.12 & 0.03 & $.23 * * *$ \\
\hline Family risk & -0.03 & 0.02 & -.07 & -0.07 & 0.02 & $-.15^{* *}$ & 0.05 & 0.025 & $.10^{*}$ \\
\hline \multicolumn{10}{|l|}{ Step 3} \\
\hline Age & -0.01 & 0.03 & -.02 & 0.04 & 0.03 & .15 & 0.02 & 0.04 & .05 \\
\hline Race & -0.02 & 0.04 & -.03 & 0.03 & 0.04 & .04 & 0.04 & 0.04 & .04 \\
\hline Community risk & 0.04 & 0.03 & .06 & -0.01 & 0.03 & -.02 & 0.03 & 0.04 & .04 \\
\hline Economic risk & -0.08 & 0.02 & $-.19 * * *$ & -0.08 & 0.02 & $-.17 * * *$ & 0.125 & 0.03 & $.24 * * *$ \\
\hline Family risk & -0.03 & 0.02 & -.08 & -0.07 & 0.02 & $-.15 * *$ & 0.05 & 0.02 & $.10 *$ \\
\hline Age $\times$ Community Risk & -0.01 & 0.02 & -.05 & -0.02 & 0.02 & -.06 & -0.05 & 0.03 & $-.16 \dagger$ \\
\hline Age $\times$ Economic Risk & 0.03 & 0.02 & $.14 \dagger$ & 0.00 & 0.02 & -.01 & -0.01 & 0.02 & -.04 \\
\hline Age $\times$ Family Risk & 0.01 & 0.02 & .06 & 0.00 & 0.02 & -.01 & 0.01 & 0.02 & .04 \\
\hline \multicolumn{10}{|l|}{ Step and model statistics } \\
\hline Step 1 & \multicolumn{3}{|c|}{$R^{2}=.005, F=1.08$} & \multicolumn{3}{|c|}{$R^{2}=.003, F=0.66$} & \multicolumn{3}{|c|}{$R^{2}=.004, F=0.87$} \\
\hline Step 2 & \multicolumn{3}{|c|}{$\begin{array}{l}\Delta R^{2}=.044, \Delta F=6.75 * * * \\
\Delta R^{2}=012 \Delta F=182\end{array}$} & \multicolumn{3}{|c|}{$\Delta R^{2}=.064, \Delta F=10.11$ **** } & \multicolumn{3}{|c|}{$\Delta R^{2}=.078, \Delta F=12.21 * * *$} \\
\hline Step 3 & \multirow{2}{*}{\multicolumn{3}{|c|}{$\begin{array}{l}\Delta R^{2}=.012, \Delta F=1.82 \\
R^{2}=061 F=3.51 * *\end{array}$}} & \multicolumn{3}{|c|}{$\Delta R^{2}=.001, \Delta F=0.19$} & \multicolumn{3}{|c|}{$\Delta R^{2}=.008, \Delta F=1.19$} \\
\hline Model & & & & \multicolumn{3}{|c|}{$R^{2}=.068, F=4.02 * * *$} & \multicolumn{3}{|c|}{$R^{2}=.089, F=5.26 * * *$} \\
\hline
\end{tabular}

Note: Race coded $1=$ White, $2=$ non-White.

$\dagger p<.10 . * p<.05 . * * p<.01 . * * * p<.001$.

in Figure 1, there was a positive association between age and licit substance use among male respondents at low levels of economic risk, such that increasing age was associated with increased substance use. In contrast, among boys at high levels of economic risk, age was not related to licit substance use. In the analyses for recent alcohol use and illicit substance use, community risk emerged as a positive predictor. In contrast, suicide attempts were associated with economic risks. Although age was a significant or marginally significant predictor of substance use on initial entry, these relations did not hold in the final models and the interactions of Age $\times$ Risk did not contribute to the models for alcohol use, illicit substance use, or suicide attempts.

Parallel analyses were conducted for female respondents. All three of the models for psychological adjustment were significant when the risk indexes were entered (Step 2), and the final models were significant (Table 7). In all three models, higher levels of economic risk were associated with poorer adjustment; in addition, family risk was associated with positive and negative emotionality (lower levels of risk were associated with higher levels of positive emotionality and lower levels of negative emotionality). Age and race were not significant at any stage of the models, and the interactions of Age $\times$ Risk did not contribute to the models.

Turning next to the models for behavioral outcomes among female respondents (Table 8), the three substance use models were significant at the final step (but not the model for suicide attempts). Economic and family risk scores were significant predictors of young women's licit substance use, and economic risk scores were associated with illicit substance use. Age was associated with both licit and illicit substance use, and remained significant in the model for illicit substance use; 
Table 8. Linear and logistic regressions predicting behavioral adjustment from demographic variables and the four risk indexes for females

\begin{tabular}{|c|c|c|c|c|c|c|c|c|c|c|c|c|}
\hline & \multicolumn{3}{|c|}{$\begin{array}{c}\text { Licit } \\
\text { Substance Use }{ }^{a}\end{array}$} & \multicolumn{3}{|c|}{$\begin{array}{l}\text { Alcohol Use } \\
\text { Last Month }^{a}\end{array}$} & \multicolumn{3}{|c|}{$\begin{array}{c}\text { Illicit } \\
\text { Substance Use }{ }^{b}\end{array}$} & \multicolumn{3}{|c|}{$\begin{array}{c}\text { Suicide } \\
\text { Attempts }^{b}\end{array}$} \\
\hline & $B$ & $S E B$ & $\beta$ & $B$ & $S E B$ & $\beta$ & $B$ & $S E$ & $\exp (B)$ & $B$ & $S E$ & $\exp (B)$ \\
\hline \multicolumn{13}{|l|}{ Step 1} \\
\hline Age & 0.10 & 0.04 & $.12 * *$ & 0.06 & 0.03 & $.09 \dagger$ & $0.34 * *$ & 0.11 & 1.41 & 0.09 & 0.10 & 1.10 \\
\hline Race & -0.19 & 0.10 & $-.09 \dagger$ & -0.21 & 0.09 & $-.11 *$ & -0.52 & 0.33 & 0.60 & 0.35 & 0.27 & 1.41 \\
\hline \multicolumn{13}{|l|}{ Step 2} \\
\hline Age & 0.08 & 0.04 & $.095 *$ & 0.05 & 0.03 & .07 & $0.31 * *$ & 0.11 & 1.36 & 0.05 & 0.10 & 1.05 \\
\hline Race & -0.19 & 0.10 & $-.09 *$ & -0.21 & 0.09 & $-.11 *$ & -0.49 & 0.34 & 0.61 & 0.37 & 0.28 & 1.45 \\
\hline Community risk & 0.04 & 0.08 & .02 & 0.12 & 0.08 & .08 & 0.24 & 0.26 & 1.27 & 0.24 & 0.24 & 1.27 \\
\hline Economic risk & 0.15 & 0.06 & $.12 *$ & 0.08 & 0.05 & .07 & $0.43 *$ & 0.18 & 1.54 & $0.34 *$ & 0.16 & 1.40 \\
\hline Family risk & 0.13 & 0.06 & $.11 *$ & 0.05 & 0.05 & .05 & -0.04 & 0.17 & 0.96 & 0.06 & 0.16 & 1.06 \\
\hline \multicolumn{13}{|l|}{ Step 3} \\
\hline Age & 0.14 & 0.08 & $.18 \dagger$ & 0.19 & 0.07 & $.27 * *$ & $0.54 *$ & 0.27 & 1.71 & $0.47 \dagger$ & 0.25 & 1.60 \\
\hline Race & -0.19 & 0.10 & $-.09 \dagger$ & -0.19 & 0.09 & $-.10^{*}$ & -0.52 & 0.34 & 0.59 & 0.38 & 0.28 & 1.46 \\
\hline Community risk & 0.04 & 0.08 & .02 & 0.12 & 0.08 & .07 & 0.28 & 0.29 & 1.32 & 0.28 & 0.25 & 1.33 \\
\hline Economic risk & 0.15 & 0.06 & $.12 * *$ & 0.09 & 0.05 & $.08 \dagger$ & $0.51 * *$ & 0.19 & 1.67 & $0.38 *$ & 0.16 & 1.46 \\
\hline Family risk & 0.13 & 0.06 & $.11 *$ & 0.06 & 0.05 & .06 & 0.00 & 0.18 & 1.0 & 0.09 & 0.16 & 1.09 \\
\hline Age $\times$ Community Risk & -0.05 & 0.06 & -.07 & -0.07 & 0.06 & -.12 & -0.03 & 0.20 & 0.97 & -0.18 & 0.18 & 0.84 \\
\hline Age $\times$ Economic Risk & 0.02 & 0.04 & .03 & 0.05 & 0.04 & .09 & -0.15 & 0.13 & 0.86 & -0.06 & 0.12 & 0.94 \\
\hline Age $\times$ Family Risk & -0.04 & 0.04 & -.07 & -0.11 & 0.04 & $-.22 * *$ & -0.02 & 0.12 & 0.98 & -0.15 & 0.12 & 0.86 \\
\hline \multicolumn{13}{|l|}{ Step and model statistics } \\
\hline Step 1 & \multirow{4}{*}{\multicolumn{3}{|c|}{$\begin{array}{l}R^{2}=.021, F=5.12 * * \\
\Delta R^{2}=.033, \Delta F=5.46^{*} \\
\Delta R^{2}=.003, \Delta F=0.47 \\
R^{2}=.057, F=3.53 * * *\end{array}$}} & \multirow{4}{*}{\multicolumn{3}{|c|}{$\begin{array}{l}R^{2}=.019, F=4.28 * \\
\Delta R=.017, \Delta F=2.58 \dagger \\
\Delta R=022, \Delta F=3.43^{*} \\
R^{2}=058, F=3.37 * *\end{array}$}} & \multirow{4}{*}{\multicolumn{3}{|c|}{$\begin{array}{l}\chi^{2}=11.63 * * \\
\chi^{2}=7.76 \dagger \\
\chi^{2}=1.83 \\
\chi^{2}=21.22^{* *} \\
\text { Nagelkerke } R^{2}=.088\end{array}$}} & \multirow{4}{*}{\multicolumn{3}{|c|}{$\begin{array}{l}\chi^{2}=2.50 \\
\chi^{2}=7.00 \dagger \\
\chi^{2}=4.19 \\
\chi^{2}=13.69 \dagger \\
\text { Nagelkerke } R^{2}=.054\end{array}$}} \\
\hline Step 2 & & & & & & & & & & & & \\
\hline Step 3 & & & & & & & & & & & & \\
\hline Model & & & & & & & & & & & & \\
\hline
\end{tabular}

Note: Race coded 1 = White, 2 = non-White.

${ }^{a}$ Continuous outcome variable.

${ }^{b}$ Dichotomous outcome variable.

$\dagger p<.10 . * p<.05 . * * p<.01 . * * * p<.001$. 


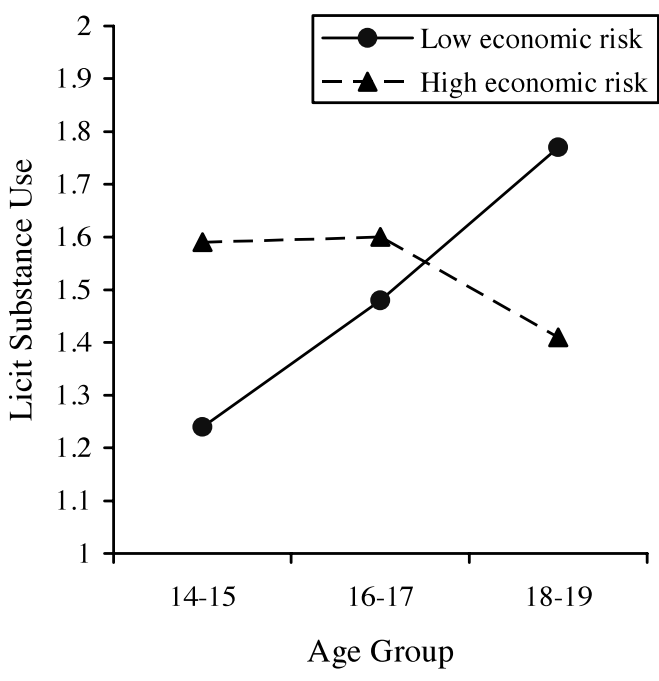

Figure 1. The interaction of age and economic risk score for young men's use of licit substances.

however, the interactions of Age $\times$ Risk did not contribute to these models. In the model for past-month alcohol use, race and age both contributed independently at the final step (White race and increasing age was associated with more alcohol use), and the interaction of Age $\times$ Family Risk was significant. To interpret the significant interaction, we graphed alcohol use in the past month as a function of age group among young women who reported family risk levels at or below the median value (i.e., 0 or 1 risk factors; $72.9 \%$ ) compared to those who reported between two and four family risk factors $(27.1 \%$; Figure 2). Among young women at low levels of family risk, increasing age was associated with increased alcohol use. In contrast, among young women at high levels of family risk, alcohol use was highest among younger girls.

Taken as a whole, these results suggest that different kinds of risks are associated with specific indicators of psychological and behavioral adjustment for young men and women.

\section{Discussion}

Around the world, young people grow to adulthood in developmental contexts that are characterized by economic deprivation and social inequality. The main goal of our analysis was

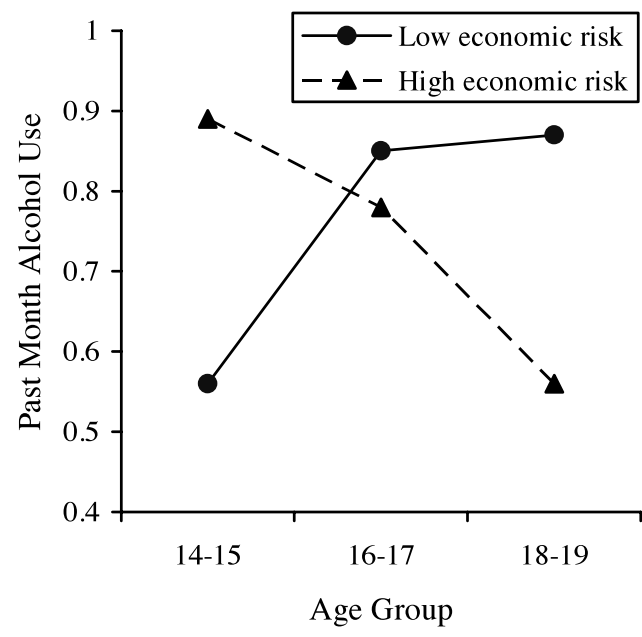

Figure 2. The interaction of age and economic risk score for young women's use of alcohol in the last month.

to examine developmental challenges experienced by impoverished Brazilian youth. We described risks in multiple domains, examined links between risks and psychological and behavioral adjustment, and examined differences in risk exposure associated with age, gender, and race. The findings contribute to the literature by providing information about an understudied population and by extending work conducted primarily in US settings to the Latin American context. Our discussion focuses both on understanding the specific findings, and on placing them within the broader developmental literature.

According to UNICEF, nearly half of the world's children are growing up in extreme poverty (Bellamy, 2004); therefore, understanding the developmentally relevant experiences of impoverished young people represents an important goal in its own right. The study on which our analysis was based was intended to advance understanding about the world's growing population of impoverished urban youth, and offered the opportunity to examine threats to development in one particular population. Descriptive analyses revealed that Brazilians youth in impoverished neighborhoods are exposed to considerable developmental risk stemming from dangerous communities, poverty, and family vulnerability. The find- 
ings are consistent with other studies conducted in Brazil. As described earlier, a similar study conducted in Northeastern Brazil (Verner \& Alda, 2004) revealed high levels of father absence, low parental education, and neighborhood violence. Another study conducted in southern Brazil with low-income 7to 9-year-olds and their mothers (Hoppe, 1998) showed that youngsters are exposed to these risks from an early age; children had experienced an average of 6.8 stressful life events, with the most common events being community violence (78\%), parental separation (59\%), family violence $(57 \%)$, housing difficulties (49\%), family death $(43 \%)$, and unemployment $(43 \%)$. Our findings indicate that older youth living in impoverished settings contend with similar issues, with implications for their psychological and behavioral adjustment.

Gender emerged as a major organizer of young people's experiences. There were no gender differences in the overall number of risks; however, young women and men reported differential exposure to particular types of risks. Young men experienced more community risks, and young women more economic and family risks. This difference may reflect the fact that traditionally, Brazilian girls and women are protected and kept close to home, whereas boys and men are allowed more freedom (for review, see Raffaelli et al., 2000). Because of this, young men and women may experience differential exposure to risks in different spheres, or be differentially aware of events in the home and the community. The difference may also reflect gender-related vulnerabilities; for example, young women in our study reported significantly more physical or sexual abuse within the family than did young men, a finding that is consistent with US findings (e.g., Clark \& Miller, 1998).

Linkages between risk exposure and psychological and behavioral adjustment also showed differential patterns for young women and men. Community risk scores were uniquely associated with adjustment in six of the seven models for male respondents (self-esteem, positive and negative emotionality, and the three substance use indicators); family and economic risk contributed to just two models each (either alone or in interaction with age). In contrast, community risk scores were never significantly associated with young women's adjustment; instead, economic (and to a lesser extent) family risks emerged as major predictors for young women. Thus, not only do young men and women report different levels of risk exposure, but also specific risks are differentially associated with adjustment. Furthermore, the proportion of variance accounted for in regression models for young men and women differed depending on the outcome, with more variance accounted for in models for psychological adjustment of female compared to male respondents. Conversely, models for behavioral adjustment accounted for more of the variance for male than female respondents.

Consistent with these findings, US-based studies have reported that girls and boys react differently to similar risks. Gender-specific responses to childhood adversity in multiple domains were reported in a longitudinal study, with girls being more likely to experience internalizing outcomes, and boys being more likely to experience externalizing outcomes (Fergusson \& Horwood, 2003). Similarly, a study of the impact of violence and victimization revealed that girls exhibited more psychological distress, whereas boys exhibited more risk behaviors (Jenkins \& Bell, 1994; see Gorham-Smith \& Tolan, 2003). However, because the majority of US studies either aggregate across multiple types of risks or focus on only one specific risk domain, differential associations between risks and outcomes have not been examined. Our findings highlight the importance of conducting more fine-grained analyses to generate a full picture of how developmental risks contribute to young people's adjustment.

Turning to developmental aspects, age was significantly related with increases in composite risk levels regardless of gender. Among young women, however, scores on the three risk indexes did not increase significantly with age. In contrast, young men reported significant age-related increases in economic and family risks, and a marginally significant increase in community risks. This gender difference may be because of the greater absolute increase in overall risk scores among males 
than among females. However, despite the general pattern of increasing risk exposure with age, there was little evidence that the impact of exposure differed for youth of different ages. Regression analyses that included interactions between risk indexes and age revealed only two significant findings. For young men, the relation between economic risk and licit substance use was moderated by age; for young women, the relation between family risk and recent alcohol use was moderated by age. In both cases, higher levels of risk were associated with elevated substance use among 14- to 15-year-olds, and lower levels of substance use among 18- to 19-year-olds. This pattern may reflect vulnerability to risk exposure among younger adolescents, who may have less effective coping strategies than older adolescents. Indeed, Margolin and Gordis (2000) suggest that the effects of family and community violence depend in part on developmental stage, and empirical research supports the notion that individuals of different ages react differently to similar risks (e.g., GorhamSmith \& Tolan, 2003).

Research conducted primarily in US settings has generated a large body of literature linking exposure to risk factors in multiple domains to psychological and behavioral adjustment (see edited volume by Luthar, 2003, for review). To our knowledge, the current study represents one of the first efforts to extend this work into the Latin American context, addressing recent calls for bringing an international perspective to the field of developmental psychopathology (Luthar \& Zelazo, 2003; Wyman, 2003). This work offers an opportunity to examine the extent to which findings obtained with US samples generalize to other settings. Although firm conclusions cannot be drawn at this stage, some initial comments are warranted. First, the overall pattern of findings indicates that, consistent with studies of impoverished and inner-city youth conducted in the United States, exposure to risk factors is linked to decrements in psychological and behavioral functioning even within a "high risk" population. Second, although differences in study designs make direct comparisons difficult, judging from the effect sizes obtained in our study, the explanatory power of risk factors appears to be similar across settings. For example, Schwab-Stone and colleagues (1995) examined linkages between three indicators of violence exposure and adjustment in models that included multiple controls. The proportion of variance accounted for was $8.4 \%$ in the model for depressed/ anxious mood and $9.1 \%$ in the model for alcohol use. In our analyses, the proportion of variance accounted for was comparable in models for girls' negative emotionality $(8.9 \%)$ and lower for past month alcohol use (5.5\%). Third, the differential impact of community, economic, and family risk levels on various aspects of young men's and women's adjustment represents a potentially important direction for future research. Prior research conducted primarily in the US has led to the conclusion that it is the total number of risks, rather than the type of risk, that is linked to negative outcomes (see Gutman et al., 2003, for review). However, our findings indicate that specific domains of risk may be differentially salient in some populations, underscoring the importance of international and comparative research aimed at elucidating how risk exposure is linked to adjustment.

\section{Limitations and Future Directions}

This study had a number of limitations. The first is that, although the study employed a rigorous sampling strategy and had a large sample size, the participation rate is unknown; thus, the extent to which findings can be generalized is unclear. Moreover, the sample was purposefully selected to represent lowincome populations, and thus the sample is not representative of the general Brazilian population. Aside from the obvious socioeconomic difference, the study sample differs from the general population in terms of race. The population of the region where our study was conducted is predominantly White $(85 \%$; Carlini et al., 2002), but under two-thirds of the study sample was White (61\%). This is consistent with the reality that poverty and race are strongly associated in Brazil; for example, prior work conducted by our team in the same city indicates that the majority of homeless youth are non-White (e.g., Raffaelli et al., 
2000). Despite these demographic differences, participants in the current study resembled the general Brazilian population in their use of substances. National household surveys reveal that in Southern Brazil, 55\% of 12 - to 17 -year-olds, and $78 \%$ of 18 - to 24 -yearolds, have ever used alcohol; 19 and 49\%, respectively, have ever used tobacco; and 3.6 and $16 \%$ have ever used marijuana (Carlini et al., 2002). Although differences in age categories make it difficult to compare directly, rates in our sample of 14- to 19-year-olds appear similar: $78 \%$ had tried beer or wine, $35 \%$ cigarettes, and 9\% marijuana. Future research should focus on replicating the study in more representative populations, as well as in other samples of impoverished youth.

A second set of limitations stems from the measures used in the analyses. Use of an existing data set involves trade-offs; we attempted to identify measures that were similar to those used in prior research, but were constrained by what was available. As a result, although we constructed measures of key study constructs that had acceptable psychometric properties, few of the measures were directly equivalent to those used in prior developmental studies. Measures limitations may explain the relatively small amount of variance accounted for in analyses predicting psychological and behavioral outcomes from risk scores. Future research using established measures is needed to provide a fuller understanding of these relations. Unfortunately, few established measures have been translated and validated for use in Brazil, which is a major obstacle for scholars attempting to contribute to the international developmental literature. Thus, one important task for future researchers is to develop and validate measures that can be used to collect data on developmental risk and adjustment in Latin America.

A third limitation is the exclusive use of self-report data. Studies of adolescents often rely on self-report assessments of psychological variables and behavior, but reliance on a single reporter increases the likelihood that associations among variables will be inflated by shared method variance. Moreover, selfreport data may be subject to presentational biases and other forms of distortion. To ad- dress these concerns, studies are needed that collect data using multiple methods (e.g., structured interviews, diagnostic assessments) from multiple reporter (e.g., parents, teachers). Replicating the current findings in multimethod, multireporter studies would lend greater confidence in the results.

A fourth limitation is the cross-sectional study design, which made it impossible to evaluate causal links between risks and adjustment. We assumed that risks preceded adjustment, an assumption supported by longitudinal studies conducted in the United States (e.g., Compas et al., 1989; DuBois et al., 1992). However, in keeping with the notion that individuals actively select their activities and environments (e.g., Lerner, 1982), risk and adjustment are likely to interrelate in a dynamic and reciprocal fashion. For example, some young people may engage in activities that increase their risk exposure, thereby contributing to maladjustment, which may in turn, result in greater risk exposure. Given the study design, we were unable to examine this type of reciprocal developmental pattern. However, in an attempt to minimize potential confounds, we tried to ensure that the risk indexes included only independent factors (Gest et al., 1999), which bolsters confidence in the assumption that risks tended to precede outcomes. However, it would be desirable to examine the reciprocal relations between risk and adjustment directly by conducting studies designed to disentangle causal pathways.

Notwithstanding these limitations, this investigation contributes an international perspective to research on development in situations of pervasive poverty. In recent decades, scholars have increasingly recognized the need to consider contextual influences on development, particularly in studies of youngsters growing up in situations characterized by social and economic risk. The current study extends this body of work into Latin America, which represents a very different context from that found in the United States and other developed nations (Welti, 2002). Young people growing up in urban poverty in Latin America experience threats to development at multiple ecological levels, with many of the risks originating outside the individual. Gaining an under- 
standing of the types of risks these youngsters experience, and learning how exposure to specific types of risks affects their well-being, will contribute to our understanding of development and psychopathology. There is an urgent need for this work, given that young people are an increasing segment of the world's population and that economic growth in developing nations is unlikely to keep pace with population increases (Fussell \& Greene, 2002). An important future direction will be to identify factors that protect impoverished youth from the negative effects of risk exposure and foster positive adaptation despite their unfavorable circumstances (i.e., resilience; Luthar et al., 2000; Masten \& Coatsworth, 1998). By adopting a resilience framework (e.g., Masten \& Powell, 2003), researchers can generate information to inform intervention programs and policy decisions aimed at improving the situation of vulnerable young people.

\section{References}

BBC News. (2004, April 30). Lula under fire on minimum wage. Retrieved October 27, 2004, from http:// news.bbc.co.uk

Bellamy, C. (2004). The state of the world's children 2005: Childhood under threat. New York: United Nations Children's Fund (UNICEF).

Bronfenbrenner, U. (1979). The ecology of human development: Experiments by nature and design. Cambridge, MA: Harvard University Press.

Bronfenbrenner, U. (2004). Making human beings human: Bioecological perspectives on human development. Thousand Oaks, CA: Sage.

Bronfenbrenner, U., \& Morris, P. A. (1998). The ecology of developmental process. In W. Damon (Ser. Ed.) \& R. M. Lerner (Vol. Ed.), Handbook of child psychology: Vol. 1. Theoretical models of human development (5th ed., pp. 993-1029). New York: Wiley.

Brooks-Gunn, J. (1995). Children in families in communities: Risk and intervention in the Bronfenbrenner tradition. In P. M. Moen, G. H. Elder, \& K. Lüscher (Eds.), Examining lives in context (pp. 467-519). Washington, DC: American Psychological Association.

Burgard, S. (2002). Does race matter? Children's height in Brazil and South Africa. Demography, 39, 763-790.

Burgard, S. (2004). Race and pregnancy-related care in Brazil and South Africa. Social Science and Medicine, 59, 1127-1146.

Carlini, E. A., Galduróz, J. C. F., Noto, A. R., \& Nappo, S. A. (2002). V levantamento domiciliar sobre o uso de drogas psicotrópicas no Brasil: Estudo envolvendo as 107 maiores cidades do país-2001 [Fifth household survey of psychotropic drug use in the 107 largest Brazilian cities-2001]. São Paulo, Brazil: Universidade Federal de São Paulo, Centro Brasileiro de Informações sobre Drogras Psicotrópicas.

Clark, D. B., \& Miller, T. W. (1998). Stress response and adaptation in children: Theoretical models. In T. W. Miller (Ed.), Children of trauma: Stressful life events and their effects on children and adolescents (pp. 327). Madison, CT: International Universities Press.

Compas, B. E., Howell, D. C., Phares, V., Williams, R. A., \& Giunta, C. T. (1989). Risk factors for emotional/ behavioral problems in young adolescents: A prospective analysis of adolescent and parental stress and symptoms. Journal of Consulting and Clinical Psychology, 57, 732-740.

Concha-Eastman, A. (2002). Urban violence in Latin American and the Caribbean: Dimensions, explanations, actions. In S. Rotker (Ed.), Citizens of fear:

Urban violence in Latin America (pp. 37-54). Piscataway, NJ: Rutgers University Press.

Cowan, P. A., Cowan, C. P., \& Schulz, M. S. (1996). Thinking about risk and resilience in families. In E. M. Hetherington \& E. A. Blechman (Eds.), Stress, coping, and resiliency in children and families (pp. 138). Mahwah, NJ: Erlbaum.

DeGoede, M., Sprujit, E., \& Maas, C. (1999). Individual and family factors and adolescent well-being: A multilevel analysis. Social Behavior and Personality, 27, 263-280.

Diversi, M., Moraes, N., \& Morelli, M. (1999). Daily reality on the streets of Campinas, Brazil. In M. Raffaelli \& R. Larson (Eds.), Homeless and working youth around the world: Exploring developmental issues. New Directions in Child Development, 85, 19-34. San Francisco, CA: Jossey-Bass.

DuBois, D. L., Felner, R. D., Brand, S. A., Adan, A. A., \& Evans, E. G. (1992). A prospective study of life stress, social support, and adaptation in early adolescence. Child Development, 63, 542-557.

Engle, P. L., Castle, S., \& Menon, P. (1996). Child development, vulnerability, and resilience. Social Science and Medicine, 43, 621-635.

Farrell, A. D., \& Bruce, S. E. (1997). Impact of exposure to community violence on violent behavior and emotional distress among urban adolescents. Journal of Clinical Child Psychology, 26, 2-14.

Fergusson, D. M., \& Horwood, L. J. (2003). Resilience to childhood adversity: Results of a 21-year study. In S. S. Luthar (Ed.), Resilience and vulnerability: Adaptation in the context of childhood adversities (pp. 130-155). Cambridge: Cambridge University Press.

Forehand, R., Biggar, H., \& Kotchick, B. A. (1998). Cumulative risk across family stressors: Short- and longterm effects for adolescents. Journal of Abnormal Child Psychology, 36, 119-128.

Fussell, E., \& Greene, M. E. (2002). Demographic trends affecting youth around the world. In B. B. Brown, R. W. Larson, \& T. S. Saraswathi (Eds.), The world's youth: Adolescence in eight regions of the globe (pp. 21-60). Cambridge: Cambridge University Press.

Galduróz, J. C. F., Noto, A. R., \& Carlini, E. A. (1997). IV levantamento sobre o uso de drogas entre estudantes de $1^{\circ}$ e $2^{\circ}$ grau de dez capitais brasileiras [Fourth survey of drug use among primary and secondary school students in ten Brasilian capital cities]. São Paulo, Brazil: Universidade Federal de São Paulo, 
Centro Brasileiro de Informações sobre Drogras Psicotrópicas.

Garbarino, J. (2001). An ecological perspective on the effects of violence on children. Journal of Community Psychology, 29, 361-378.

Garmezy, N., \& Tellegen, A. (1984). Studies of stressresistant children: Methods, variables, and preliminary findings. In F. Morrison, D. Keating, \& C. Lord (Eds.), Applied developmental psychology (Vol. 1, pp. 231-287). New York: Academic Press.

Gest, S. D., Reed, M. J., \& Masten, A. S. (1999). Measuring developmental changes in exposure to adversity: A Life Chart and rating scale approach. Development and Psychopathology, 11, 171-192.

Giacomoni, C. H. (2002). Bem-estar subjetivo infantil: Conceito de felicidade e construção de instrumentos para avaliação [Subjective well-being in childhood: Concepts of happiness and the construction of assessments tools]. Unpublished dissertation, Universidade Federal do Rio Grande do Sul, Porto Alegre, Brazil.

Gorham-Smith, D., \& Tolan, P. (1998). The role of exposure to community violence and developmental problems among inner-city youth. Development and Psychopathology, 10, 101-116.

Gorham-Smith, D., \& Tolan, P. (2003). Positive adaptation among youth exposed to community violence. In S. S. Luthar (Ed.), Resilience and vulnerability: Adaptation in the context of childhood adversities (pp. 392-413). Cambridge: Cambridge University Press.

Gutman, L. M., Sameroff, A. J., \& Cole, R. (2003). Academic growth curve trajectories from 1st grade to 12th grade: Effects of multiple social risk factors and preschool child factors. Developmental Psychology, 39, 777-790.

Hoppe, M. W. (1998). Redes de apoio social e afetivo de crianças expostas a situações de risco. [Social and emotional support networks of children exposed to risk situations]. Unpublished master's thesis, Universidade Federal do Rio Grande do Sul, Porto Alegre, Brazil.

Instituto Brasileiro de Geografia e Estatística. (2003). Indicadores Sociais Municipais-2000 [Municipal social indicators-2000] (Tables 15, 16, 19). Retrieved May 13, 2003, from http://www.ibge.gov.br

Instituto Brasileiro de Geografia e Estatística. (2004). Sintise de indicadores sociais 2003 [Synthesis of social indicators 2003]. Retrieved January 6, 2005, from http://www.ibge.gov.br

Jenkins, E. J., \& Bell, C. C. (1994). Violence exposure, psychological distress, and high-risk behaviors among inner-city high school students. In S. Friedman (Ed.), Anxiety disorders in African-Americans (pp. 76-88). New York: Springer.

Koller, S. H., Ribeiro, J., Cerqueira-Santos, E, Morais, N. A., \& Teodoro, M. L. (2005). Juventude brasileira: Comportamentos de risco, fatores de risco e de proteção [Brazilian youth: Risk behaviors, risk and protective factors]. Washington, DC: World Bank.

Krug, E. G., Dahlberg, L. L., Mercy, J. A., Zwi, A. B., \& Lozano, R. (Eds.). (2002). World report on violence and health. Geneva, Switzerland: World Health Organization. Retrieved January 6, 2005, from http://www. who.org

Laurent, J., Catanzaro, S. J., Joiner, T. E., Rudolph, K. D., Potter, K. I., Lambert, S., et al. (1999). A measure of positive and negative affect for children: Scale devel- opment and preliminary validation. Psychological Assessment, 11, 326-338.

Lerner, R. M. (1982). Children and adolescents as producers of their own development. Developmental Review, 2, 342-370.

Luthar, S. S. (1991). Vulnerability and resilience: A study of high-risk adolescents. Child Development, 62, $600-616$

Luthar, S. S. (Ed.). (2003). Resilience and vulnerability: Adaptation in the context of childhood adversities. Cambridge: Cambridge University Press.

Luthar, S. S., Cicchetti, D., \& Becker, B. (2000). The construct of resilience: A critical evaluation and guidelines for future work. Child Development, 71, 543-562.

Luthar, S. S., \& Zelazo, L. B. (2003). Research on resilience: An integrative review. In S. S. Luthar (Ed.), Resilience and vulnerability: Adaptation in the context of childhood adversities (pp. 510-549). Cambridge: Cambridge University Press.

Margolin, G., \& Gordis, E. B. (2000). The effects of family and community violence on children. Annual Review of Psychology, 51, 445-479.

Masten, A. S., \& Coatsworth, J. D. (1998). The development of competence in favorable and unfavorable en vironments: Lessons from research on successful children. American Psychologist, 53, 205-220.

Masten, A., \& Garmezy, N. (1985). Risk, vulnerability and protective factors in developmental psychopathology. In B. B. Lahey \& A. E. Kazdin (Eds.), Advances in clinical child psychology (pp. 1-52). New York: Plenum Press.

Masten, A. S., Miliotis, D., Graham-Bermann, S. A., Ramirez, M., \& Neeman, J. (1993). Children in homeless families: Risks to mental health and development. Journal of Consulting and Clinical Psychology, 61, 335-343.

Masten, A. S., \& Powell, J. L. (2003). A resilience framework for research, policy, and practice. In S. S. Luthar (Ed.), Resilience and vulnerability: Adaptation in the context of childhood adversities (pp. 1-25). Cambridge: Cambridge University Press.

Raffaelli, M. (1999). Street youth in Latin America: A developmental review. Interamerican Journal of Psychology, 32, 7-28.

Raffaelli, M., Koller, S. H., Reppold, C., Kuschick, M., Krum, F. M. B., \& Bandeira, D. R. (2000). Gender differences in Brazilian street youth's family circumstances and experiences on the street. Child Abuse and Neglect, 24, 1431-1441.

Raffaelli, M., \& Larson, R. (Eds.). (1999). Homeless and working youth around the world: Exploring develop mental issues. New Directions in Child Development, 85. San Francisco, CA: Jossey-Bass.

Rizzini, I. (1996). Street children: An excluded generation in Latin America. Childhood: A Global Journal of Child Research, 3, 215-234.

Rizzini, I., Barker, G., \& Cassaniga, N. (2002). From street children to all children: Improving the opportunities of low-income urban children and youth in Brazil. In M. Tienda \& W. J. Wilson (Eds.), Youth in cities: A cross-national perspective (pp. 113-137). Cambridge: Cambridge University Press.

Rosenberg, M. (1979). Conceiving the self. New York: Basic Books.

Sameroff, A., Gutman, L. M., \& Peck, S. C. (2003). Adaptation among youth facing multiple risks: Prospective research findings. In S. S. Luthar (Ed.), Resilience and vulnerability: Adaptation in the context of child- 
hood adversities (pp. 364-391). Cambridge: Cambridge University Press.

Schwab-Stone, M. E., Ayers, T. S., Kasprow, W., Voyce, C., Barone, C., Shriver, T., et al. (1995). No safe haven: A study of violence exposure in an urban community. Journal of the American Academy of Child and Adolescent Psychiatry, 34, 1343-1352.

Turner, R. J., \& Lloyd, D. A. (2003). Cumulative adversity and drug dependence in young adults: Racial/ ethnic contrasts. Addiction, 98, 305-315.

Umaña-Taylor, A. J., \& Fine, M. A. (2001). Methodological implications of grouping Latino adolescents into one collective ethnic group. Hispanic Journal of Behavioral Sciences, 23, 347-362.

Verner, D., \& Alda, E. (2004). Youth at risk, social exclusion, and intergenerational poverty dynamics: A new survey instrument with application to Brazil. World Bank Policy Research Working Paper No. 3296. Retrieved January 6, 2005, from http://econ.worldbank. org/files/35472_wps3296.pdf
Waiselfisz, J. J. (2004). Mapa da violência IV: Os jovens do Brasil [Map of violence of Brazilian youth]. Brasilia, Brazil: UNESCO.

Welti, C. (2002). Adolescents in Latin America: Facing the future with skepticism. In B. B. Brown, R.W. Larson, \& T. S. Saraswathi (Eds.), The world's youth: Adolescence in eight regions of the globe (pp. 276306). Cambridge: Cambridge University Press.

World Bank. (2003). Overview: Poverty in Latin America and the Caribbean. Retrieved January 6, 2005, from http://www.worldbank.org/lacpoverty

Wyman, P. A. (2003). Emerging perspectives on context specificity of children's adaptation and resilience: Evidence from a decade of research with urban children in adversity. In S. S. Luthar (Ed.), Resilience and vulnerability: Adaptation in the context of childhood adversities (pp. 293-317). Cambridge: Cambridge University Press. 